\title{
The Urban Studio
}

A strategic alliance between Academia and Practice has been established in downtown Chicago. This unique collaboration between the University of Illinois Urbana-Champaign and VOA Associates Incorporated has yielded a new program: The Urban Studio of the University of Illinois Urbana Champaign.

\section{KEVIN HINDERS}

University of Illinois Urbana

Champaign

\section{INTRODUCTION}

This collaboration has resulted in more meaningful projects and a more significant experience for both students and professionals compared to traditional studio approaches. With our recent success in mind, we are working to further strengthen our interactions to the mutual benefit of the University of Illinois School of Architecture and VOA. The opportunities are as endless as the energy, talent and ideas of our participants. In this paper, we will document how this program came to be, its current successes and challenges, and some of our exciting ideas for the future.

\section{BACKGROUND}

Founded in 1969, the global architecture, planning and interior design firm VOA Associates Incorporated believes in a collaborative design approach in its practice. VOA continually seeks out opportunities to interact with and contribute to the community, and academia in particular. VOA architects are currently engaged with academic practice at a number of institutions nationwide and in Venice, Italy. A global firm, VOA has offices in Beijing, Chicago, Highland Indiana, Los Angeles, New York, Orlando, Shanghai, São Paulo and Washington, D.C. VOA considers itself a multinational firm that provides the personal attention of a boutique studio. VOA engages in a collaborative design process. Immersing ourselves in each client's culture, we create spaces that tell a meaningful story about the people who bring them to life.

\section{INCEPTION}

For a number of years, the ISoA had been interested in launching a studio in Chicago which sought to explore urban design problems in the city. In the summer of 2013 the faculty of the ISoA and members of the City of Chicago mayor's office agreed to explore the mutual benefits that could arise from student/faculty participation on city projects. Associate Professor \& Architect, Urbanism Program Chair and The Chicago Studio Coordinator, Kevin Hinders then made inquiries through the City of Chicago about finding a space for a new Urban Studio program in Chicago. He was shown several spaces, but found none that satisfied ISoA requirements. 


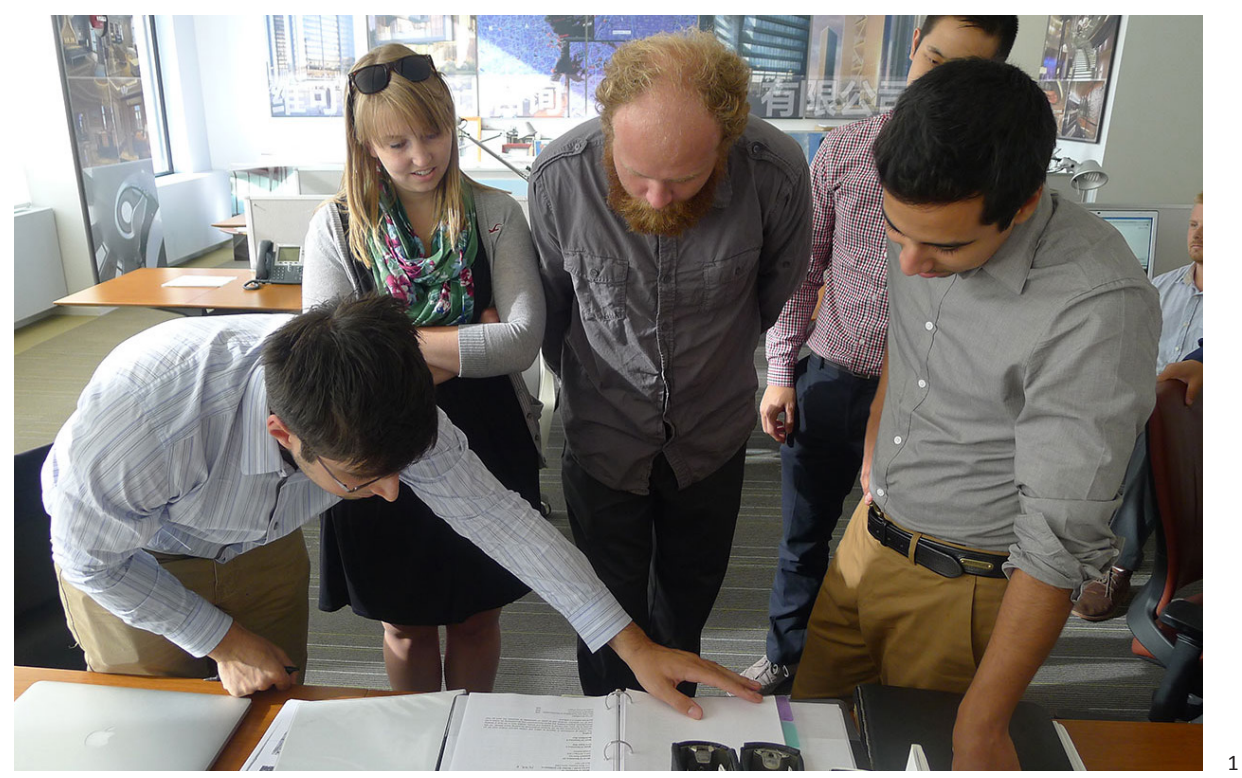

\section{STUDIO SPACE}

VOA CEO and Chairman Michael Toolis, AIA, LEED AP became aware of the university's search for studio space in Chicago. He immediately thought of the portion of VOA's own space on the 13th floor of its offices in the historic 224 S Michigan building, the Santa Fe Building. Toolis met with Hinders and they toured the space. Toolis, an alumnus of the Architecture program at the University of Illinois himself, felt strongly that hosting students from the program in VOA's office space would benefit both VOA and the Urban Studio program. An agreement was reached for the Urban Studio to use a portion of the available space. VOA hosted the Urban Studio beginning in the Fall 2014 semester and agreed to a 5 year commitment.

Due to subleasing and time constraints, the VOA space on the 13th floor was unavailable for the first semester's investigation in the fall of 2014. Instead VOA hosted studio and classes for the Chicago Studio in their space on the 14th floor. This initial studio was afforded unique opportunities to interact with VOA employees. Since that time the designated space has been built out which affords a healthy interaction with VOA and other professionals in the Chicago area.

\section{STUDENTS, SPACE AND PARTNERSHIPS}

Urban Studio students are pursuing post-graduate degrees in architecture from the ISoA, . For the Urban Studio, they relocate to Chicago for one semester. Students live in diverse and lively parts of the city such as Lakeview and Wrigleyville. Some students choose to commute from their homes. While here, they spend their weekdays in the studio space itself, on tours and exploring the city. It's an immersive experience in designing for a modern city. Typically, the Urban Studio hosts 12-14 students per semester.

Not only does VOA provide the physical space for the program, but they provide professional expertise and informal consulting throughout the semester. Initially VOA's Melissa Ogden served as the primary liaison to the program. Since January, 2015, VOA's Shannon Piatek has served as VOA's primary point of contact to the program. VOA facilitates significant professional-student interaction in the form of reviews, informal critiques of projects and portfolios, charrettes of VOA's professional projects, lunch time Q\&As, Pecha Kuchas and industry lunch and learns. Sharing space and interacting informally is powerful for both students and employees. The experience makes VOA's practice richer and allows VOA to witness firsthand the talent and trends emerging from our universities. It gives emerging professionals opportunities for exposure to our diverse profession.

Figure 1: Urban Studio students, 2014 


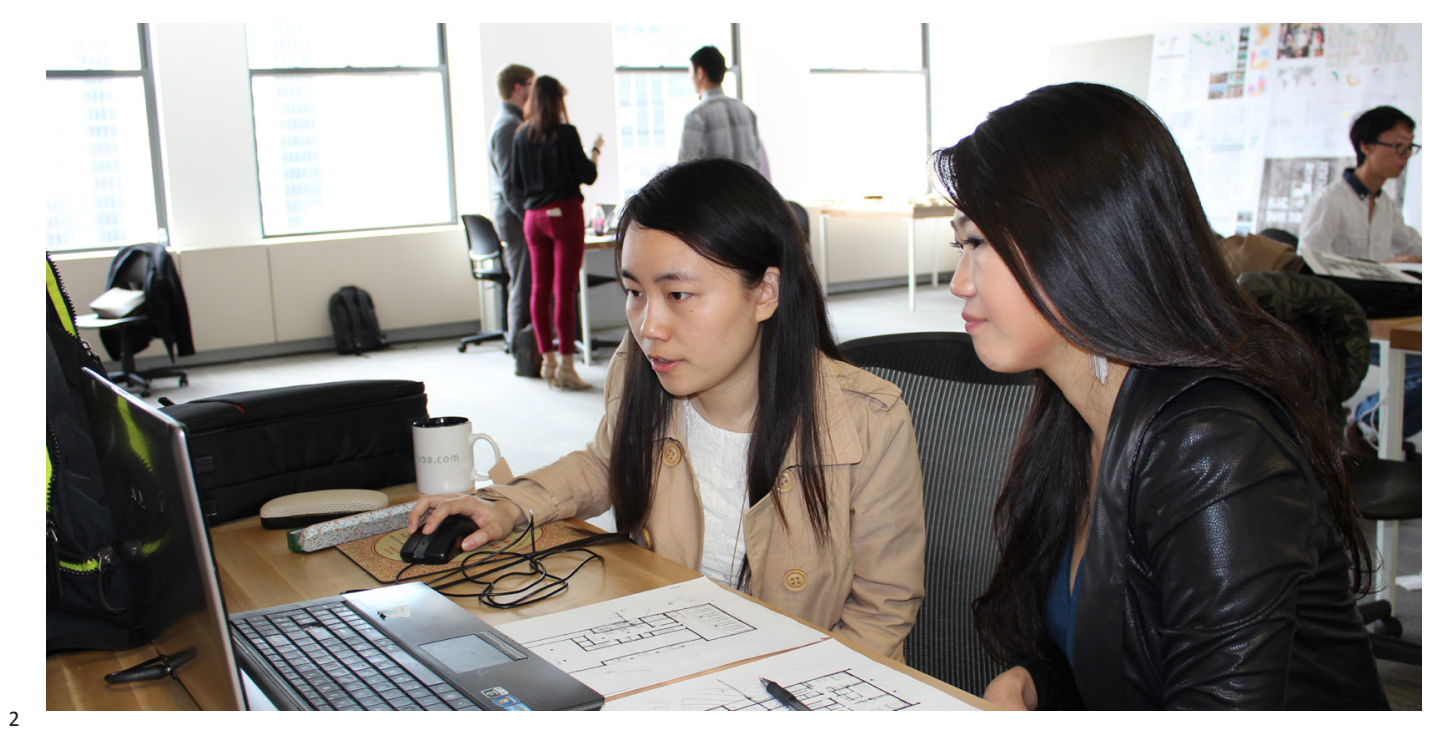

Partnerships with the City of Chicago Mayor's Office and the Chicago Department of Planning and Development and the participation of numerous architecture firms in student visits and critiques make the Urban Studio possible. Additional firms involved in the first semesters include Solomon Cordwell and Benz, Holabird and Root, Booth Hansen, Gensler, Studio GC, Legat Associates, Nagle Hartray Architecture, SOM, Klein and Hoffman, Perkins + Will, Adrian Smith + Gordon Gill Architecture, Ross Barney Architects, Studio Gang and Goettsch Partners.

\section{STUDIO PROJECT AS COLLABORATION MECHANISM AND VEHICLE FOR LEARNING} The Urban Studio is designed to align with the curriculum of the Illinois School of Architecture.

Students in the Urban Studio participate in three to four courses of study during their semester in the city: Experience the Urban Space, Experience the Architecture and Experience the Firms.

\section{Experience the Urban Space: Project Development}

The inaugural student project, Fall 2014, involved the investigation of a 200 -acre site in close proximity to the Illinois Medical District and Fulton Market Innovation District, a site that includes the United Center and the soon to be completed new Malcom X Community College. The Urban Studio developed an urban design strategy/proposal for the area which sought to harmonize with the existing structures of the city and anticipate the future needs of residents and visitors while providing a new neighborhood quality which has been sacrificed by social and economic factors over the past fifty years.

The Spring 2015 Urban Studio group is examining transit oriented development for Chicago's Albany Park neighborhood. The city is looking for an innovative ways to promote development as well as the use of public transit. One of America's most diverse neighborhoods, Albany Park suffers from acute traffic congestion. Two teams of students spent the first half of the semester studying the demographics, history, architecture, culture and transport issues in the neighborhood and developing master plans for redevelopment. The second half of the semester had student teams developing detailed designs for new architecture in the area to support a smart transit-oriented development program.

The most significant advantage of the new program shines through in this project development. The Urban Studio students are able to experience and study the sites and populations

Figure 2: Urban Studio students learn from visiting industry professionals related to these projects firsthand. "It's nice that the site is right here, we can just commute down," says one student regarding the Albany Park project. 


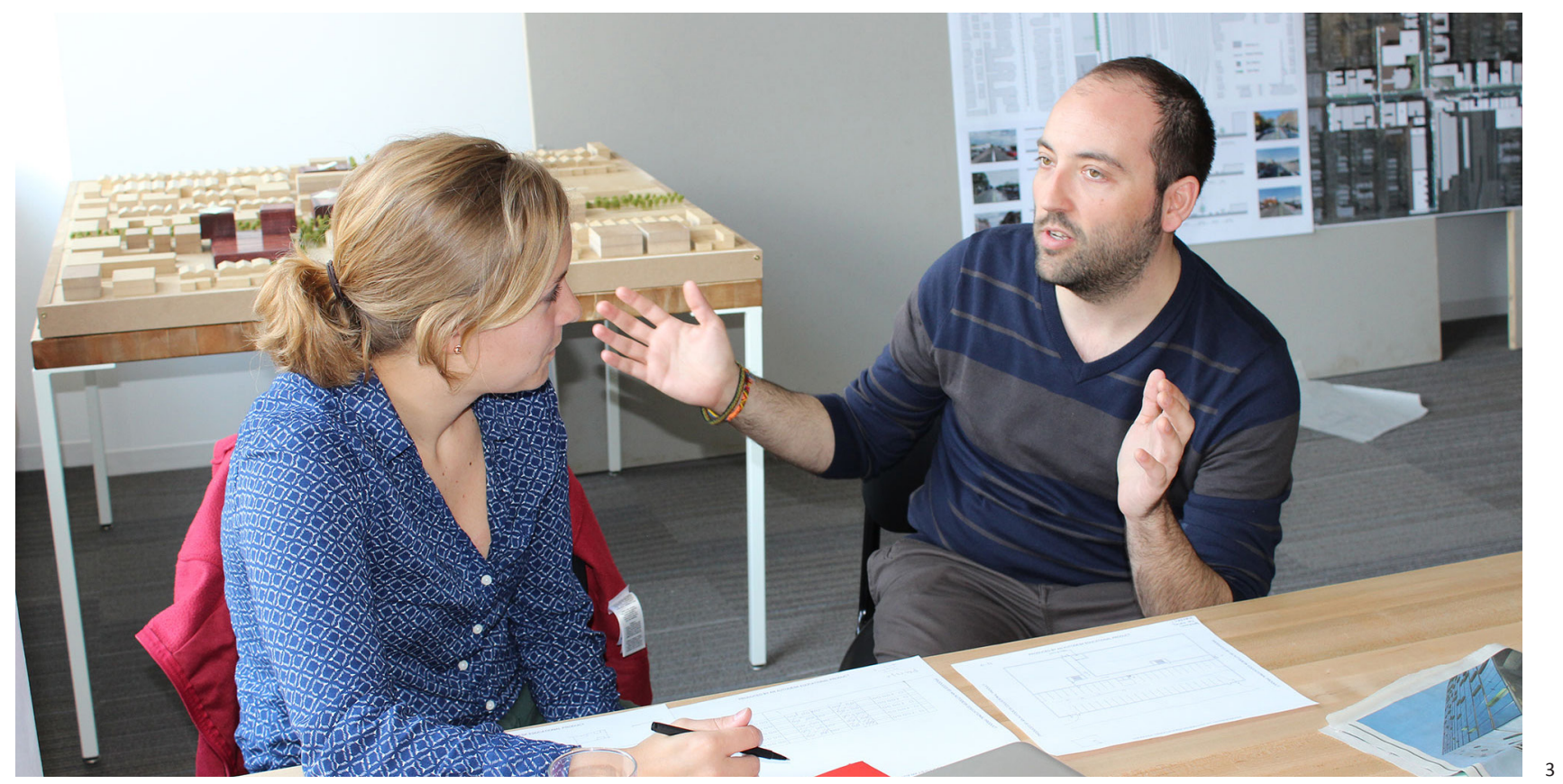

Student projects also benefit from the feedback on projects in progress from professionals working in architecture, development and planning. The Urban Studio regularly welcomes representatives from VOA and other major architecture firms for on-the-boards presentations and desk critiques of student projects in progress. In the studio space, students can show boards of research, planning and design and receive detailed feedback in person. Professionals offer their honest critiques of the concepts and presentation in this informal setting.

Students have noted that this feedback is invaluable and of a different quality than what they receive from peers or instructors while studying in Urbana.

Embedded in a studio on the 13th floor or VOA's Chicago offices, students of the Urban Studio have a close-up perspective on how a global design firm operates every day. Students participating in the studio can informally utilize professional architects and designers of VOA as a sounding board for their design concepts and studio projects. Students can get advice on job hunting in the field as well as seeing how important a cultural fit can be between architect and firm.

\section{Experience the Architecture: Tours and exploration}

In the fall semester, two seminars directly engaged the city as place. An Urban Morphology course offered insights into the typologies used in the Chicago block structure and the variety of urban conditions and responses throughout the city. In an Urban Phenomenology Seminar taught by Professor Brian Hammersley directly engaged the places in the city that give greater haptic experience to citizens and visitors in the city. This semester, under the direction of Professor Joy Malnar, students each week visit various noteworthy (often new and contemporary) architectural projects in Chicago (The Poetry Foundation at 61 W Superior St, EnV at 161 W Kinzie, Coast at 345 E Wacker, Virgin Hotel at $203 \mathrm{~N}$ Wabash to name a few). Additionally, students tell us that they use their free time to explore the city's neighborhoods and restaurants, gaining an understanding of Chicago's urban fabric as residents. Student feedback inspired to see close-up the historic and recent examples of architecture which they've studied in school. Students are also given the opportunity to volunteer during to the Chicago Architecture Foundation's Open House Chicago event. In recognition of their time, the CAF offers the participating students free tickets for their architectural tours. 


\section{Experience the Firms: Office visits and critiques}

On a designated day each week, Urban Studio students visit and tour the offices of major global architecture firms. The firms previously listed hosted students and faculty with the expressed questions: What are your firms ideals? What methods does the firm use to deliver on these ideals to both the client and the general public? These two questions formed the basis for both the firm's presentation and, we are told by the participating firms, a healthy bit of introspection. In addition, individuals from firms agreed to informally mentor a student from the studio. Some examples of mentoring included meeting for lunch, discussing portfolios and general knowledge sharing of Chicago and its activities. The weekly visit aspect of the program allows students to learn about these firms in greater detaileverything from their building type and market specialization to firm size, culture and mission. These firm visits give students unparalleled perspective on the profession as practiced in Chicago. Architects and designers from these firms are guests on open studio days, offering critiques and advice on project work. Visiting a variety of firms gives students experiences to which they can compare and contrast their VOA experience in terms of culture, projects and operations.

\section{ALLIANCES AND SUPPORTERS}

\section{City of Chicago Mayor's Office and Department of Planning} and Development

Urban Studio students meet with representatives from the City of Chicago Planning and Development department in developing their projects. Because of the groundwork set by ISoA's outreach, the ISoA Urbanism Program now undertakes urban design projects identified by the Mayor's Office as applied research investigations. Students work with the Chicago Department of Planning and Development representative Brad McConnell to identify the city's goals and objectives and then determine the strengths and weaknesses inherent in a location. Mr. McConnell serves as client for the semester while encouraging an investigation based upon the realities of land ownership and economics.

\section{ROOSEVELT UNIVERSITY}

The ISoA works with students and faculty from the Marshall Bennett Institute of Real Estate of Roosevelt University which assists the Urban Studio in gaining an understanding of the economic (pro forma, development strategies, etc.) realities of their design work while providing a worthwhile exercise for the Roosevelt Real Estate class. This academy-to-academy partnership is important for the Urban Studio program. In the future, it is expected that an iterative process will develop to assist students from both groups as they seek to broaden their education.

\section{SIGNS OF SUCCESS... WITH ROOM TO GROW}

\section{Benefits Realized}

VOA benefits from access to talent, ideas, energy of the next generation of architects.

- VOA has benefitted from a first look at the talent emerging from the School of Architecture, University of Illinois Urbana Champaign. This gives VOA a glimpse at trends, skills and interests of the next generation of architects entering the profession.

- VOA architects and designers were able to see and draw inspiration and best practice data from the example of how Urban Studio participants utilize research, technol-

Figure 4: Site visits bring students close-up perspective on Chicago's most recent architecture. ogy, demographic data and resources in the City of Chicago and elsewhere in their projects. 
- VOA gets access to current thinking in academia on architecture and planning.

- The experience makes VOA's practice richer, creates opportunities for emerging professionals to understand the realities of our diverse profession and allows VOA to witness firsthand the talent and trends emerging from our universities.

- VOA has recently extended a full-time offer to Jake Eilermann as Intern Architect working in its hospitality group.

- Provide leadership positions for up and coming VOA staff

- Through critiques and stimulating discussions focused on design and design theory, VOA is able to reinforce the importance of design to its staff

- Students benefit from their access to the city, its architecture, project sites, professionals and their firms as well as numerous networking opportunities.

- Students have benefitted from the partnership in their exposure to Chicago, the profession and critiques from professionals.

- Students have been able to create their projects with input from the City of Chicago, architectural professionals, developers and community members. They have been able to observe urban locations for their projects over time and become familiar with their culture and demographics.

- Students have been able to observe the day-to-day life of VOA and learn about the culture and practice of other major architecture firms.

- Some students have been able to use the exposure to firms to take on part-time internships in concert with their Urban Studio studies.

- Studio participants gain access to major architecture firms and relevant professional industries in Chicago.

- Students gain an understanding of the types of firms (culture, size, project focus) they wish to work for.

- Students lay the foundation for professional and personal relationships that will continue throughout their careers.

\section{STUDENT QUOTES:}

\section{On the Studio Experience:}

"I learned a ton in this studio. Being in the city provided tremendous opportunity for learning from examples and from advice (both in and out of reviews) from firms. Working with the city and working on a realistic Chicago Project is a huge plus for starting to work and finding a job... Professor did an excellent job of simultaneously teaching urban design so we felt confident in our solution."

"This studio has been by far the most valuable since it provided lots of information that would be used in every course.".

\section{On the Professional Development Experience:}

"This course is AWESOME! Worth running the Chicago Program for this alone. As long as the student has the desire, it is invaluable as a networking tool. Extremely useful to understand what the firms are about before I start applying for jobs. Mentorship is also very worthwhile."

"People here want to help young professionals. The networking aspect is great."

"I like the architectural tours of buildings. And in visiting firms, we can get into the firm and listen to their values." 


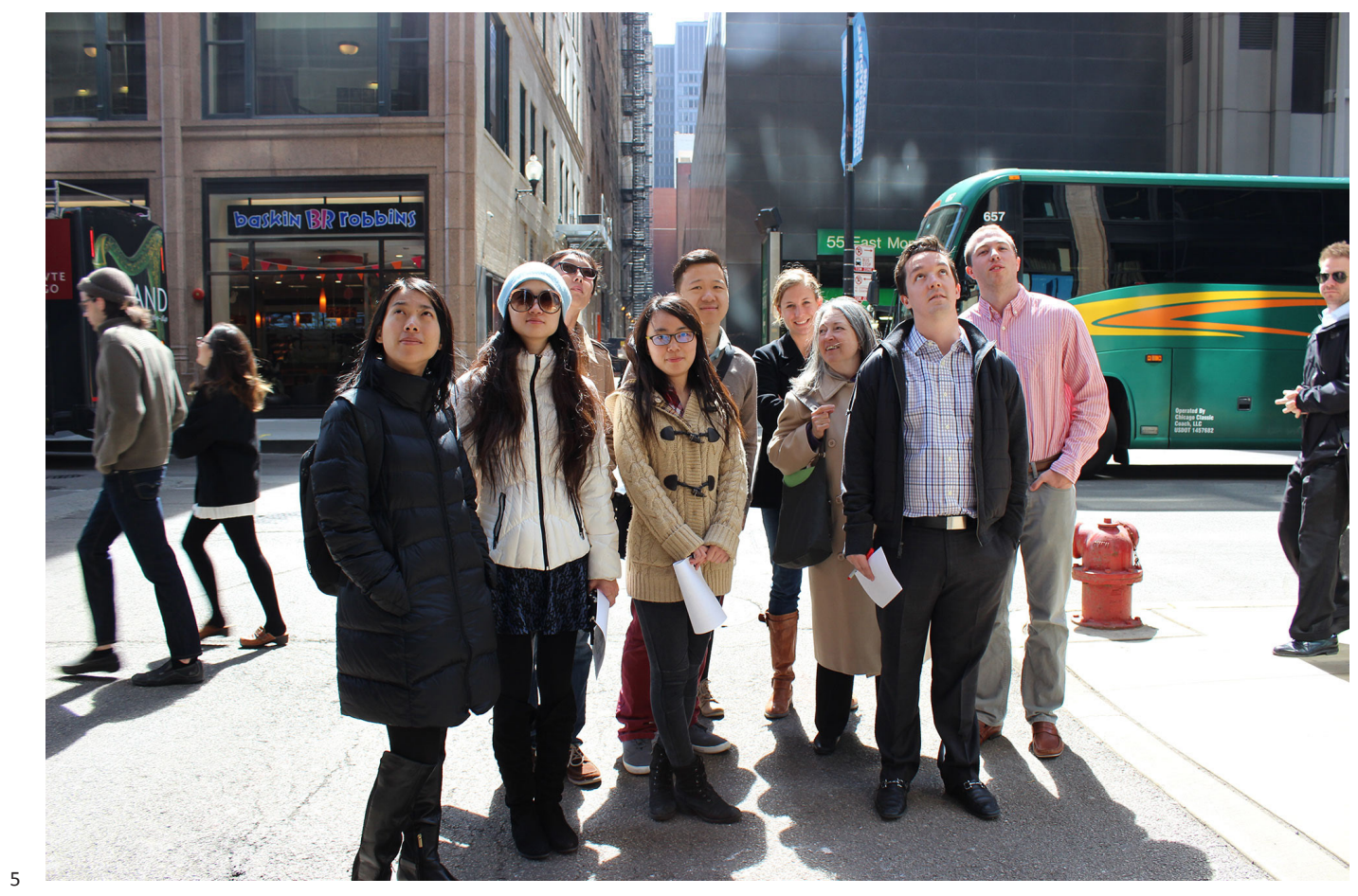

"Being at VOA has given me a better idea of where I want to be after I graduate. Also, it's a really nice place."

\section{THE FUTURE OF COLLABORATION}

Now that we have significant informal collaboration, should we look at pushing this even further? With experience we have begun to look at aspects of the program that create opportunities for closer collaboration and a fuller experience for students. We are optimistic and enthusiastic about the potential for growth and integration. The VOA Urban Studio of the University of Illinois Urbana Champaign will continue to evolve and develop. Several students have expressed interest to further push the integrated experience within the Urban Studio and VOA. Others have expressed a desire for more capability within the studio space itself.

Below, we have noted some of the most significant adjustments and additions we have outlined for the program and the timeline for implementing them.

\section{BUILD COLLABORATION INTO STRUCTURED SCHEDULE}

One idea is to formalizing weekly or biweekly interaction. This will help to integrate the more timid students while expanding the greater support network for them within VOA. We plan to implement this in the Fall 2015 studio.

\section{MENTOR/BUDDY SYSTEM}

The Urban Studio program will connect students with VOA employees in a more formal way as buddies or mentors. We plan to implement this in the Fall 2015 studio.

\section{PROJECT INCUBATOR}

The Urban Studio will be used as an incubator on certain project types or projects experimenting with a new process. This will allow us to further explore the benefits of collocation. The studio will function as a true project team to either work on a real building project or

Figure 5: With firm visits, Urban Studio students gain valuable perspective on careers in architecture. work on a competition project. We plan to implement this as opportunities arise in Spring 2016. Potential benefits could include: revenue generation (or other in kind services) for the 
University; if match with the right project this could be very beneficial for client at no or low cost; reinforce VOA culture of design and collaboration.

\section{RESEARCH AND DEVELOPMENT LABORATORY}

The Urban Studio could be used as a laboratory for experimental design research. Students and VOA could collaborate on conceptual design projects investigating the frontier of architecture and design. These designs would have educational and inspirational value for participants and great value in marketing and promoting both the firm and the Urban Studio.

\section{CONTENT CREATION/MARKETING/DOCUMENTATION}

Efforts have been undertaken to document the Urban Studio in text, interviews, graphics and photography and produce publications (print and online) to publicize the program.

\section{IN CONCLUSION}

The Urban Studio established in downtown Chicago is a strategic alliance between academia and practice. In its first year, this collaborative alliance in the immersive environment of Chicago and the office of an architecture firm yielded more meaningful project work and a more significant overall experience for students than a typical classroom studio. It also provided beneficial insights and access to talent and ideas for the firm and visiting professionals. Acknowledging this initial success, however, there is much room for growth and improvement in the details and scope of the program. There are many further opportunities to explore for uniting and experimenting with this particular colocation. The experience gained in the first year of this alliance will be applied to refinements and new aspects of the program.

Greater integration between the Urban Studio and VOA itself will deepen the experience for both participants. VOA will have a chance to better understand the character of the next generation of architects emerging from the Illinois School of Architecture. And students will gain a fuller appreciation of VOA's collaborative design process and a better understanding of the profession as a whole. Casual interaction and chance encounters are known to enhance the educational experience and further research. These chance interactions can be further promoted in future iterations of the Urban Studio program.

Under the leadership of the ISoA Urbanism Program, partners VOA Associates Incorporated, the City of Chicago Mayor's Office and Department of Planning and Development, Roosevelt University, participating firms and others have made the success of the Urban Studio possible. Thanks are due to these partners for making this innovative program possible. 